\title{
Experimental study of radiator, underfloor, ceiling and air heater systems heat emission performance in TUT nZEB test facility
}

\author{
Karl-Villem Võsa ${ }^{1 *}$, Andrea Ferrantelli ${ }^{1}$ and Jarek Kurnitski ${ }^{1,2}$ \\ ${ }^{1}$ Nearly Zero Energy Buildings Research Group, Ehitajate tee 5, 19086 Tallinn, Tallinn University of Technology, Estonia \\ ${ }^{2}$ Aalto University, School of Engineering, Rakentajanaukio 4 A, FI-02150 Espoo, Finland
}

\begin{abstract}
This paper reports the results of different heat emitter system measurements, which were carried out at the nZEB test facility near Tallinn University of Technology in early 2018. Radiators, underfloor heating, air heaters and radiant ceiling panels are studied as coupled with different control schemes ranging from ON-OFF to PI-type control. The objective is to assess and quantify the control accuracy and thermal comfort parameters among different configurations.

Scheduled heating dummies are used to simulate internal heat gains within the otherwise unoccupied test rooms. Along with outdoor temperature variation, the heating demand is therefore constantly changing and the control systems are continuously adjusting the heat output to maintain the desired indoor air temperatures. Control accuracy is then determined from the temperature deviations against this set value. Air stratification within the room is assessed with vertical temperature gradient calculations from measured air temperatures at different heights. The operative temperature at the point of expected occupancy is calculated from surrounding air and enclosing surface temperatures.

The quantified results provide a comprehensive comparison between the different system configurations, enabling further energy simulations in related software packages since these parameters directly influence the energy usage within a system.
\end{abstract}

\section{Introduction}

A wide variety of different heat emitters is available for building heating solutions [1, 2, 3, 4]. While the heating load needed within a building should be systemindependent (i.e. only dependent on ambient conditions), the actual energy used can vary to some degree depending on the chosen system. The position, size, mode of heat transfer, control scheme etc can indeed vary greatly between different configurations [3]. Some systemspecific parameters and variables, such as vertical air temperature gradients [1] as a result of stratification, operative temperature difference from air temperature and control accuracy are known to have a significant effect on annual energy consumption [4]. This configurationspecific performance difference poses an interesting research question - how to quantify and attribute these differences in energy usage to specific emitter types and products on a comparable and standardised basis. Indeed, the incentive should be to use the system with the lowest energy usage.

The European standard EN 15316 provides an approach of quantifying this in terms of the room temperature set-point variation [5]. If a parameter causes an increase in annual energy consumption, this is accounted for by raising the set-point in the related calculations or simulations. Such set-point increments are then summed up and added to the initial room temperature set-point.

The present study aims at measuring and calculating some of the input parameters that are required for the performance assessment prescribed by the CEN TC 130 standardisation technical committee agenda. These parameters can then be used in an annual energy simulation, in order to compute the set-point increments for different system configurations.

In the following, we accordingly determine for specific product categories the experimental input and model calibration data that will be used in dynamic

${ }^{*}$ Corresponding author: karl-villem.vosa@taltech.ee 
simulations of heat emission parameters in the European reference room

\section{Method}

In this study, control accuracy and thermal comfort parameters for different heat emitter systems are calculated from experimental measurements carried out at the Tallinn University of Technology nZEB test facility in March 2018. The measurements were carried out for the following emitter types:

- 11-type panel radiators of size $300 \times 1200 \mathrm{~mm}$ with a nominal heat output of $307 \mathrm{~W}$ at design flow temperatures of $55 / 45^{\circ} \mathrm{C}$, placed under windows.

- Wet installation underfloor heating (UFH) with pePEX piping $(20 \times 2.0 \mathrm{~mm}, 300 \mathrm{~mm}$ intervals $)$ at a depth of $40 \mathrm{~mm}$ in screed, nominal heat output of 55 $\mathrm{W} / \mathrm{m}^{2}$ at design flow temperatures of $34 / 29{ }^{\circ} \mathrm{C}$. The UFH covers the whole floor and no additional floor covers or finishing lays on top of the screed.

- Three radiant ceiling panels with a size of $2400 \times 600$ $\mathrm{mm}$, nominal heat output of 418 Watts at design flow temperatures of $55 / 45^{\circ} \mathrm{C}$.

- Air heater system with a $1500 \mathrm{~W}$ duct heater.

These emitter types are coupled with ON/OFF- and PI-type controllers for heat output regulation (see e.g. [6] for a detailed description).

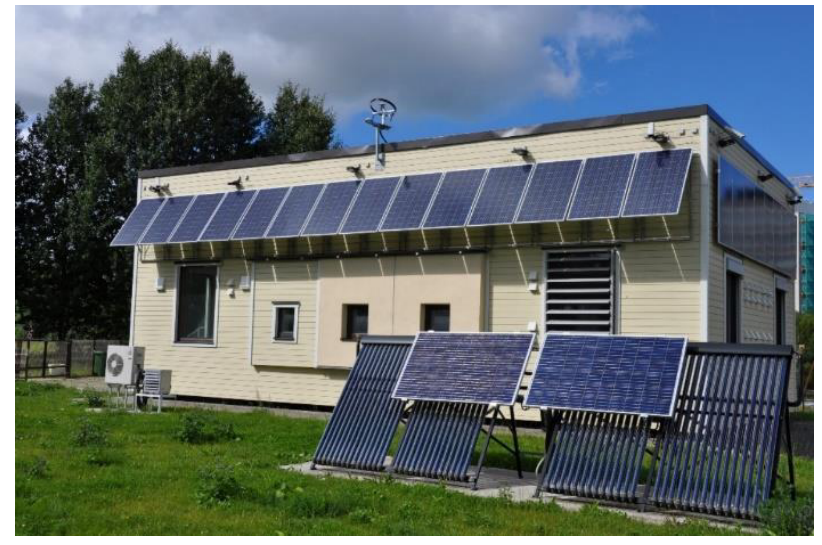

Fig. 1. Tallinn University of Technology nZEB test facility [4].

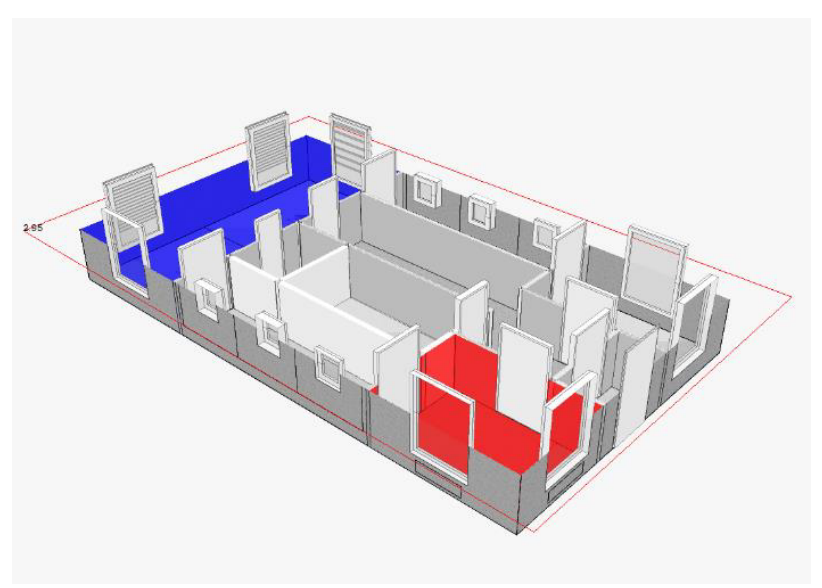

Fig. 2. Measurement rooms - R5 in red, R9 in blue.
The measurements were carried out in two different rooms within the test facility - a smaller $10 \mathrm{~m}^{2}$ room $\mathrm{R} 5$ (Radiator, UFH, radiant ceiling panels) and a larger $30 \mathrm{~m}^{2}$ room R9 (Radiator, UFH, air heater). The exclusion of radiant ceiling panels in $\mathrm{R} 9$ and air heater in $\mathrm{R} 5$ is not an oversight, as limitations within the test facility rooms did not allow for these systems to be set up properly.

A residential ventilation air flow rate of $0.71 /\left(\mathrm{sm}^{2}\right)$ was used in all the tests. The rooms were served by a central air handling unit with a supply air temperature of $18{ }^{\circ} \mathrm{C}$ (which was then increased in the air heater system to higher temperatures according to the indoor air temperature). The set-point for indoor air temperature was $21{ }^{\circ} \mathrm{C}$ in all tests.

Internal heat gains in the form of heating dummy assemblies consisting of a light bulb, fan and metal casing were placed into the test rooms to simulate a more dynamic heat load. The heating load is thus variable, depending on outdoor conditions and state of the dummies. This helps to better quantify the control accuracy parameters between emitter systems with different thermal mass and control schemes.

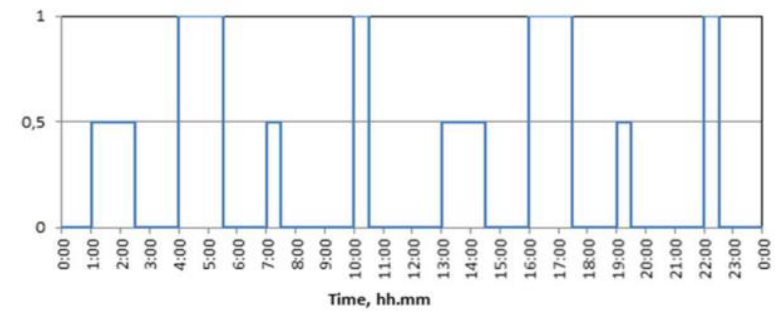

Fig. 3. Heating dummy $24 \mathrm{~h}$ profile. $1=150 \mathrm{~W}$ for R5, $450 \mathrm{~W}$ for R9.

Over 40 different temperature sensors were installed within the two rooms. Two measurement stands with measurement points at heights of $0.10,0.60,1.10,1.70$ and $2.90 \mathrm{~m}$ were placed into each room for vertical temperature distribution measurements, one in the centre of the room and one at $0.6 \mathrm{~m}$ from an external window. All internal and external surfaces were also equipped with a temperature sensor for mean radiant temperature and operative temperature calculations.

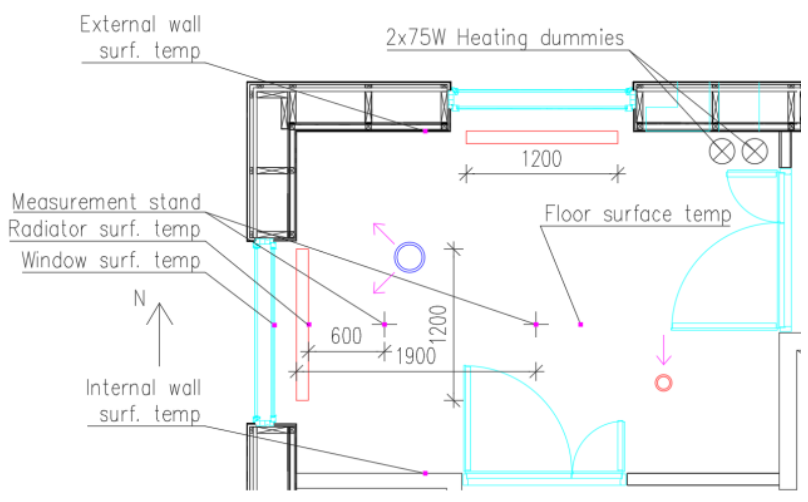



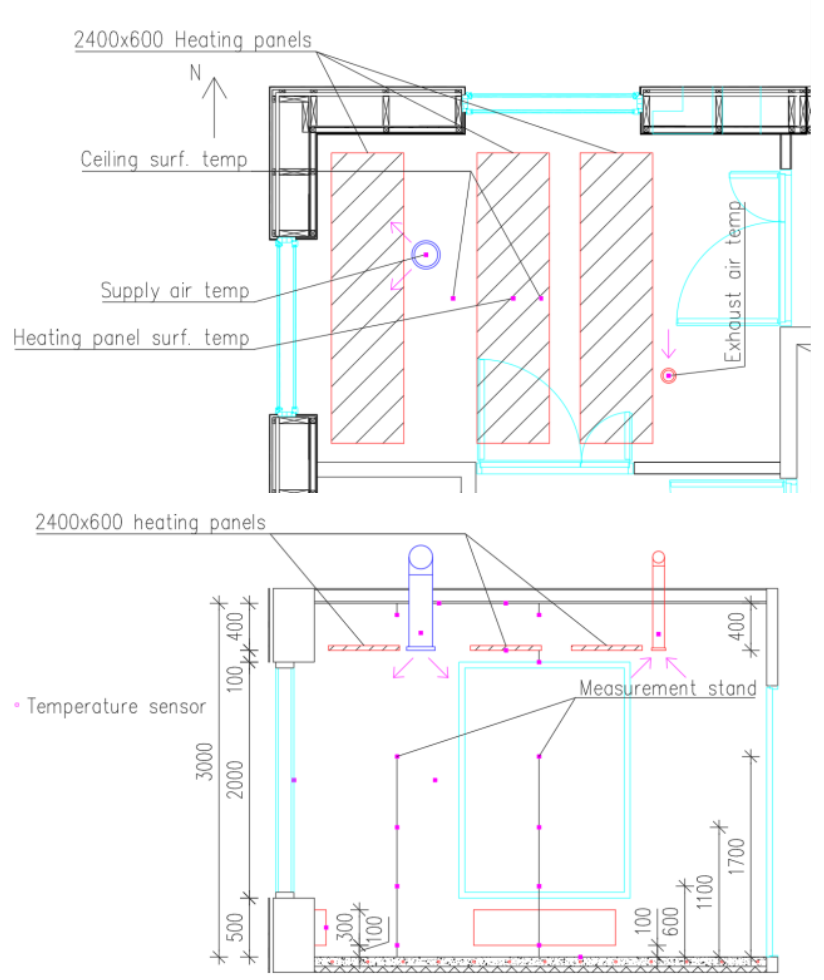

Fig. 4. Plan (above), ceiling (middle) and section (below) views of R5.
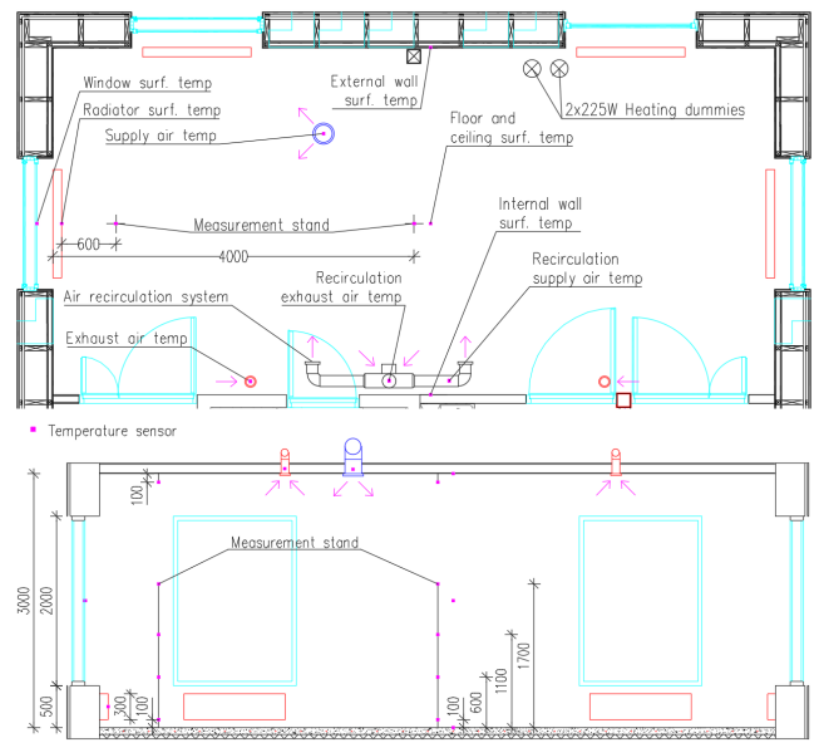

Fig. 5. Plan (above) and section (below) views of R9.

Vertical temperature gradients within the enclosure are calculated from air temperatures,

$$
G=\frac{t_{2}-t_{1}}{h},
$$

where $t_{2}$ and $t_{1}$ are air temperatures $0.10 \mathrm{~m}$ from the ceiling and floor, respectively, and $h$ is the distance between the two measurement points.

The operative temperature is calculated according to ISO 7726:1998 [7] as the average of surrounding air temperature $t_{\text {air }}$ and mean radiant temperature $t_{m r t}$ at the point of occupancy,

$$
t_{o p}=\frac{t_{a i r}+t_{m r t}}{2} .
$$

The mean radiant temperature is calculated from the enclosing surface temperatures,

$$
t_{m r t}=\sqrt[4]{\sum T_{n}^{4} F_{p \rightarrow n}}
$$

where $T_{n}$ is the n-th surface temperature and $F_{p \rightarrow n}$ is the view factor from the $\mathrm{n}$-th surface to the point of occupancy. Throughout this paper, the occupant is assumed to be seated in the middle of the room at a height of $0.60 \mathrm{~m}$. The temperature control accuracy is also assessed for air temperatures measured at this height.

For control accuracy assessment, the control variation is calculated according to EN-15500-1:2017 [8] as

$$
C V=\frac{t_{\max }-t_{\min }}{2},
$$

where $t_{\max }$ and $t_{\min }$ are the maximum and minimum air temperatures within the room during the measurement. In other words, it is quantified as half of the peak-to-peak amplitude of the temperature variation within the calculation period.

As the measurements of different systems were not conducted concurrently but rather after one another, the effect of solar radiation has to be accounted for within the measurements. To eliminate the effects of solar radiation on the measurement results, mainly due to the direct effect of direct sunlight on the indoor air temperature and the indirect effect due to thermal energy capacity within the enclosure, only night-time results (9 p.m. - 5 a.m.) are used in the upcoming analysis.

Each of the emitter and control combinations was measured for 2-5 consecutive days. All the following results are presented as averages for the measurement periods.

\section{Results}

From Figs. 6-7, the deviation in indoor air temperature during the measurements can be read for different emitter system setups. Sharp peaks in air temperature can be noticed at several time points corresponding to the periodical switching of the heating dummies. This was the intended outcome, as indeed the air temperature steadystate variation would not be very high, nor it would be very indicative of the control accuracy in practical applications. In occupied buildings, the internal gains are in fact highly variable, and here we are interested in the response of the system to this variable heating load.

As expected, the $\mathrm{CV}$ values are higher in the case of ON/OFF-type controllers, with differences between the two controller types ranging from 0.05 to $0.21{ }^{\circ} \mathrm{C}$. The thermal mass of the emitter was the second major reason for differences, with higher amounts of thermal mass leading to higher $\mathrm{CV}$ values. This is also expected, since such a system has a slower response to dynamic changes. Accordingly, the radiator had the lowest $\left(0.36^{\circ} \mathrm{C}\right.$ and 0.39 ${ }^{\circ} \mathrm{C}$ for PI-control) and the UFH had the highest $\left(0.52{ }^{\circ} \mathrm{C}\right.$ and $0.62{ }^{\circ} \mathrm{C}$ for $\mathrm{ON} / \mathrm{OFF}$-control) $\mathrm{CV}$ values. 


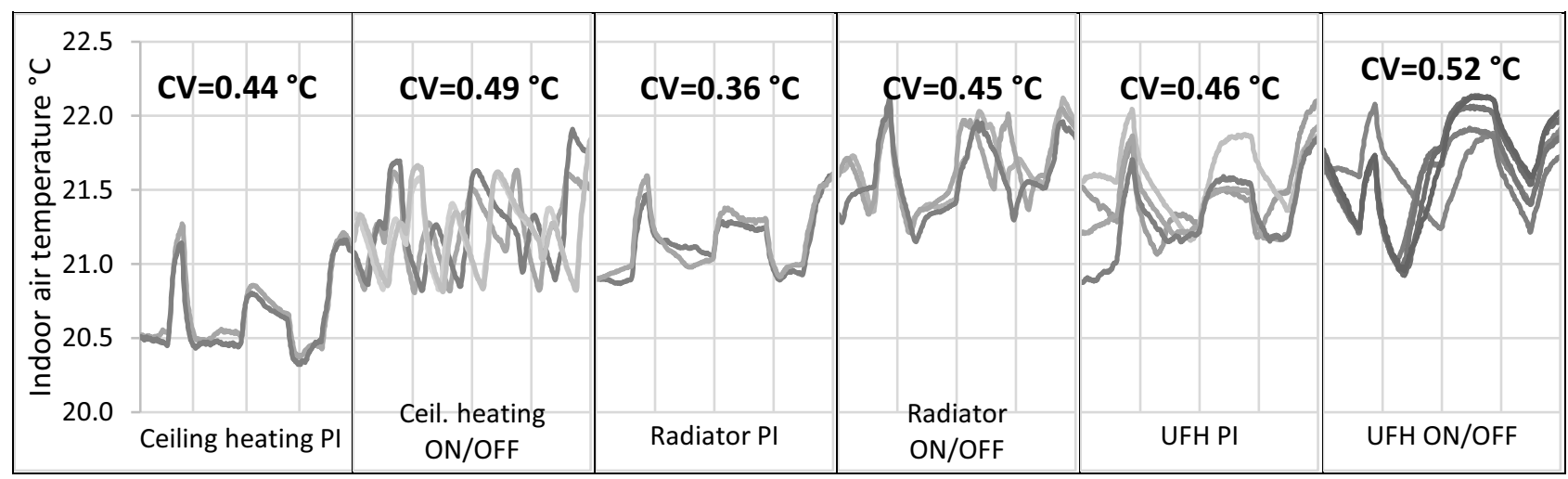

Fig. 6. Daily control variation of different emitter systems in R5, 9 p.m. to 5 a.m.

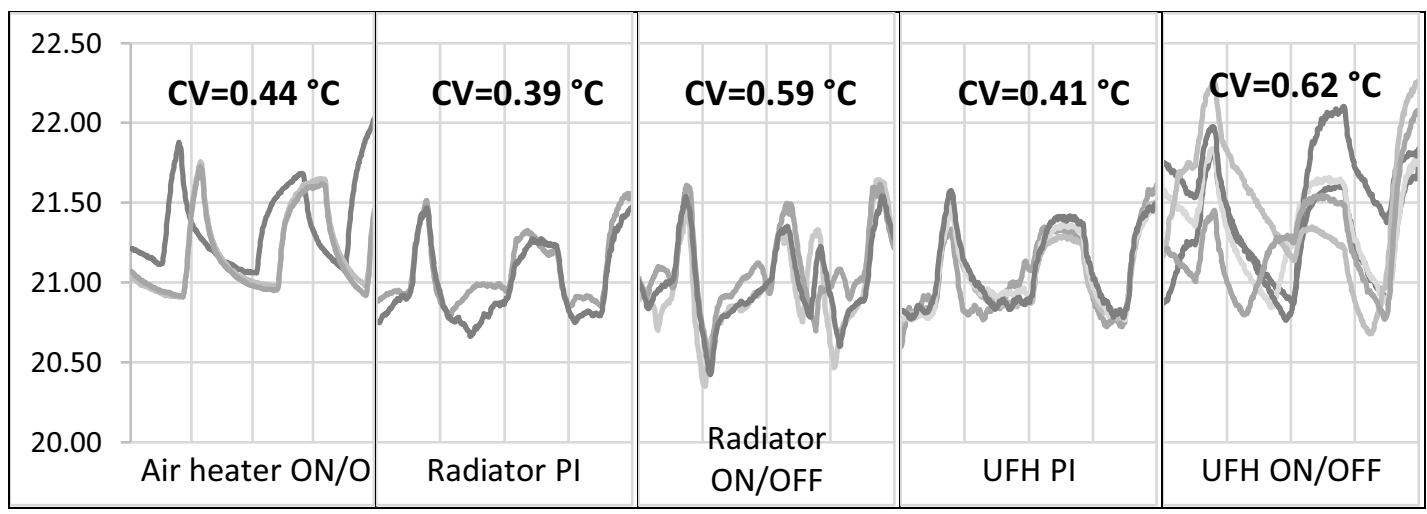

Fig. 7. Daily control variation of different emitter systems in R9, 9 p.m. - 5 a.m.

The vertical temperature distribution for the different configurations can be seen in Figs. 8-11. Results for the same emitter type are displayed on the same figure as the stratification effect is independent of the control system used. Lengths of $0.6 \mathrm{~m}, 2.0 \mathrm{~m}$ and $4.0 \mathrm{~m}$ in the figures indicate the distance from the external wall (see Figs. 4-5 for the location of measurement stands).

The results within a single emitter type are consistent, with the maximum difference of $0.22{ }^{\circ} \mathrm{C} / \mathrm{m}$ occurring for radiators. No noticeable difference is observed between the measurement stand in the middle of the room and the one closer to the external wall. Likely the chosen distance of $0.6 \mathrm{~m}$ was not close enough to quantify the effect that a colder external surface has on the vertical temperature distribution. Measured surface temperatures at the floor and ceiling (or ceiling panel surface in the case of radiant panels) are also shown for reference at $\mathrm{z}=0.00$ and 2.70/3.00 m.

No significant amount of stratification was exhibited for UFH $\left(\bar{G}=0.04{ }^{\circ} \mathrm{C} / \mathrm{m}\right)$, with a warm surface at the bottom of the room in combination with forced ventilation creating the best conditions for effective mixing of air within the enclosure. A modest average gradient of 0.13 ${ }^{\circ} \mathrm{C} / \mathrm{m}$ was observed for radiators. In the case of air heater and radiant ceiling panels, the air temperature is locally higher underneath the ceiling, and due to buoyancy effects the air mixing within the room is poor. This leads to average vertical temperature gradients of 0.36 and 0.62 ${ }^{\circ} \mathrm{C} / \mathrm{m}$ for air and radiant panels respectively.

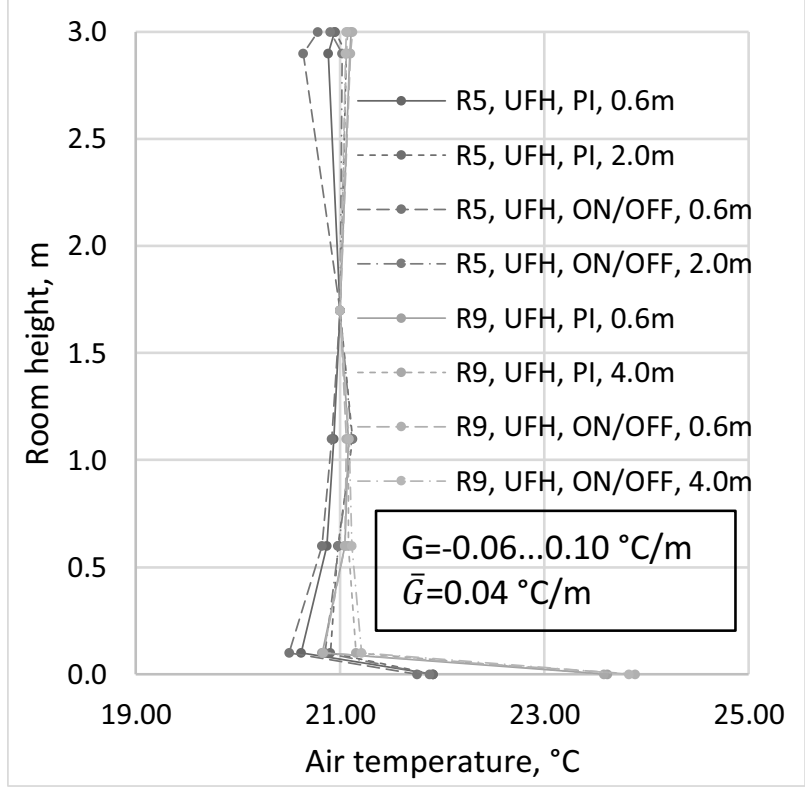

Fig. 8. Vertical temperature stratification of UFH. 


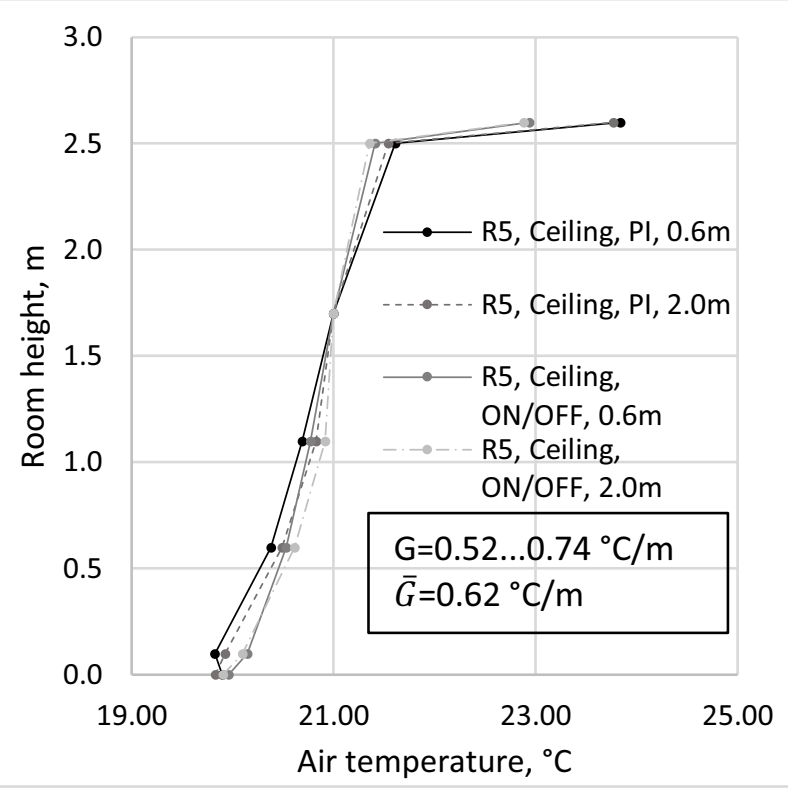

Fig. 9. Vertical temperature stratification of radiant ceiling panels, measured at $2.60 \mathrm{~m}$ as the panels were installed at a height of $2.70 \mathrm{~m}$.

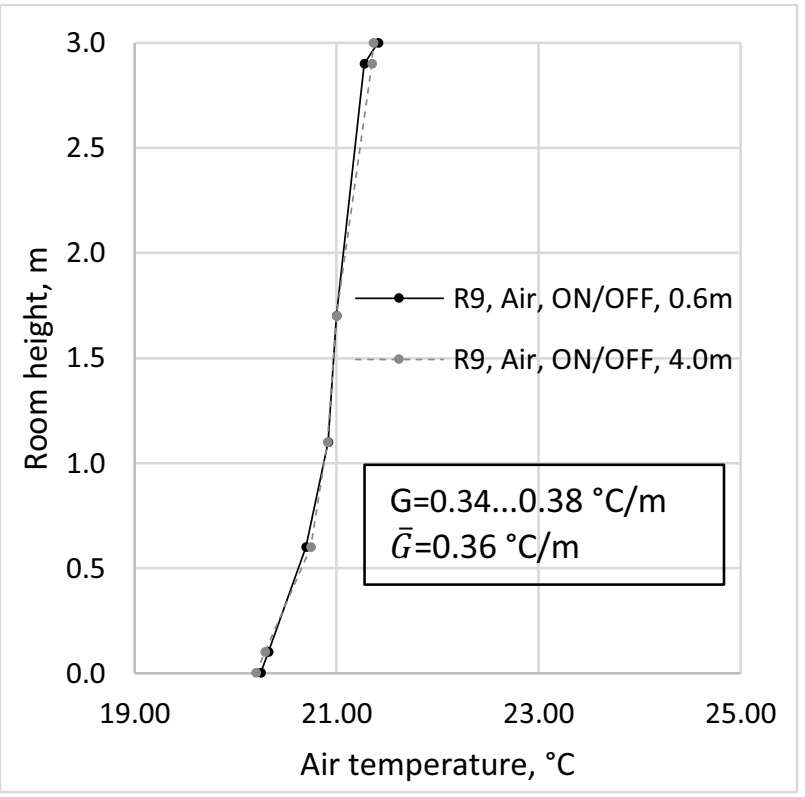

Fig. 10. Vertical temperature stratification of air heater.

The differences in air and operative temperature are shown in Figs 12-17. Surface temperatures (or in case of air heater, the supply air temperatures) are also shown in the graphs. In general, these two quantities are in opposite phases to each other, e.g. higher surface temperatures lead to lower differences in the temperature differential between the air and operative temperature and vice versa.

The UFH has the lowest $t_{a i r}-t_{o p}$ values of 0.01 and $0.45{ }^{\circ} \mathrm{C}$ for rooms $\mathrm{R} 5$ and $\mathrm{R} 9$ respectively. This is the expected result, as the operative temperature is dependent on the surface temperatures according to Eqs. 2-3 [7]. Among the emitter systems considered, the UFH has the highest surface area; a large, warm surface will have a greater effect on the mean radiant temperature, and thus on the operative temperature. The difference between R5 and R9 can be explained with a higher floor-to-wall surface ratio in R9.

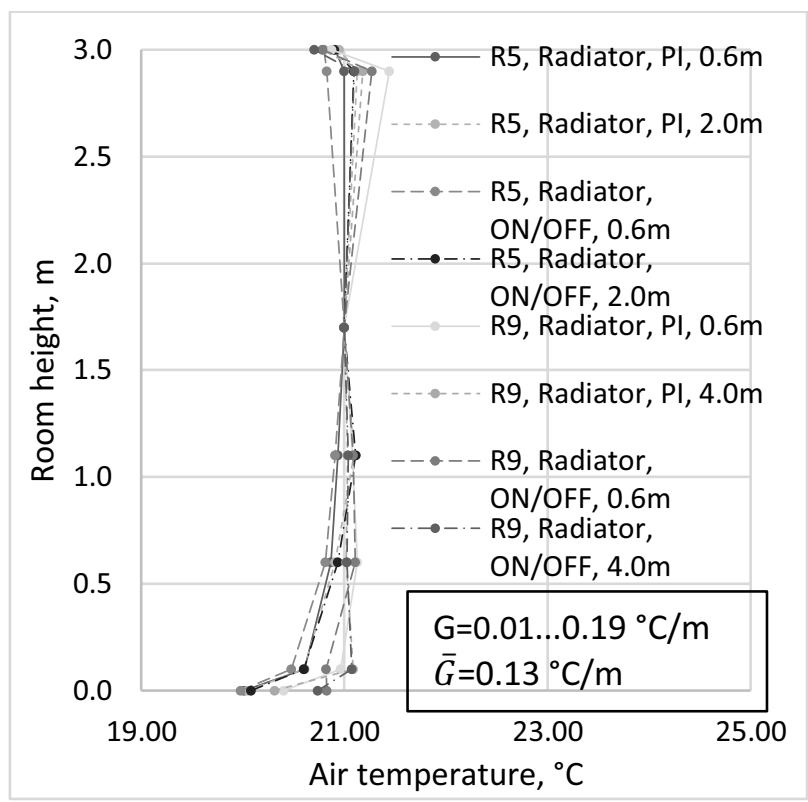

Fig. 11. Vertical temperature stratification of radiators.

The air heater has a similar $t_{a i r}-t_{o p}$ value of $0.01{ }^{\circ} \mathrm{C}$, quite likely because the warm air underneath the ceiling is heating up also the ceiling surface considerably, affecting the mean radiant temperature similarly to the UFH. Temperature differentials of 0.11 and $0.20 / 0.26{ }^{\circ} \mathrm{C}$ were observed respectively for the radiant ceiling panels and radiators. Size is therefore the main discerning factor among the emitter systems, when addressing this temperature differential, with larger surfaces performing better.

In general, it is beneficial to have minimal control variation, stratification and temperature differential between indoor air and operative temperature [9]. Accounting for this, it can be concluded from Table 1 that the UFH is likely the emitter with the best performance. However, all these parameters occur concurrently within a room and the combined effect on energy consumption can only be assessed through annual simulations or measurements where all these parameters are accounted for.

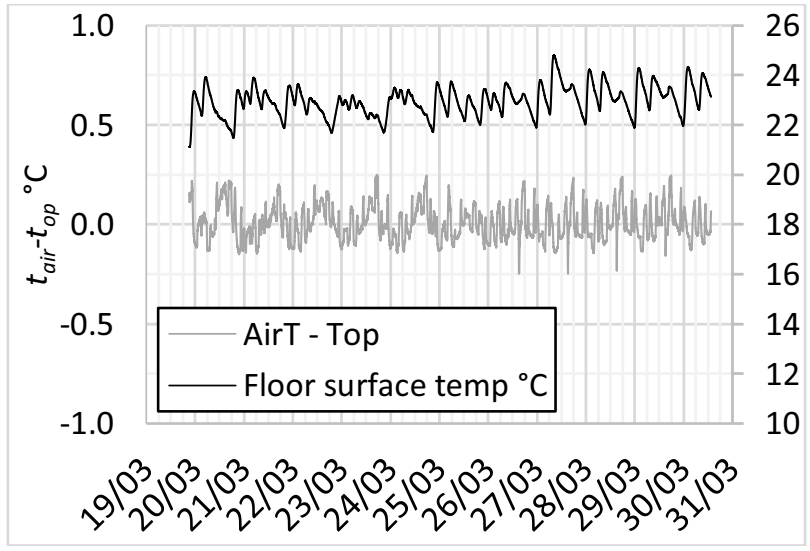

Fig. 12. R5 UFH $t_{\text {air }} \mathrm{t}_{\mathrm{op}}$ difference. 


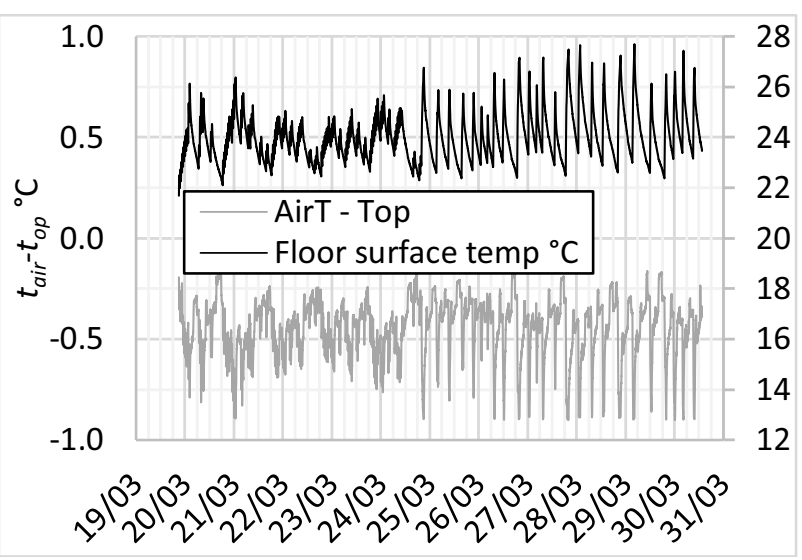

Fig. 13. R9 UFH tair-top difference.

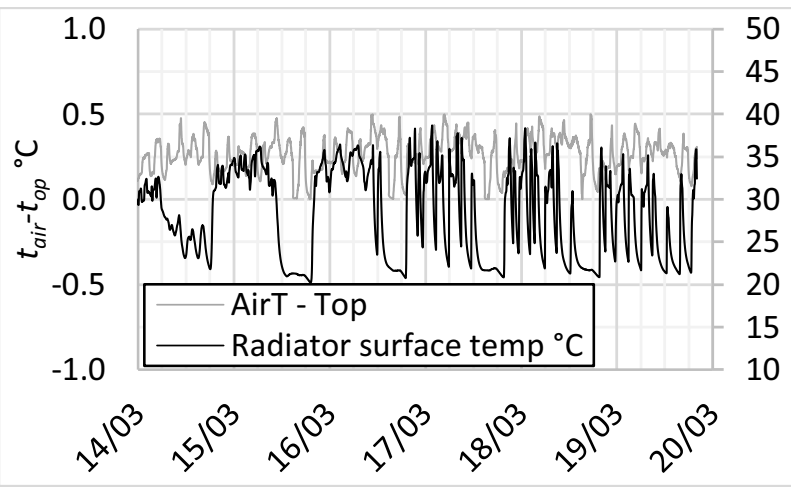

Fig. 14. $R 5$ radiator $t_{\text {air }} \mathrm{t}_{\text {op }}$ difference.
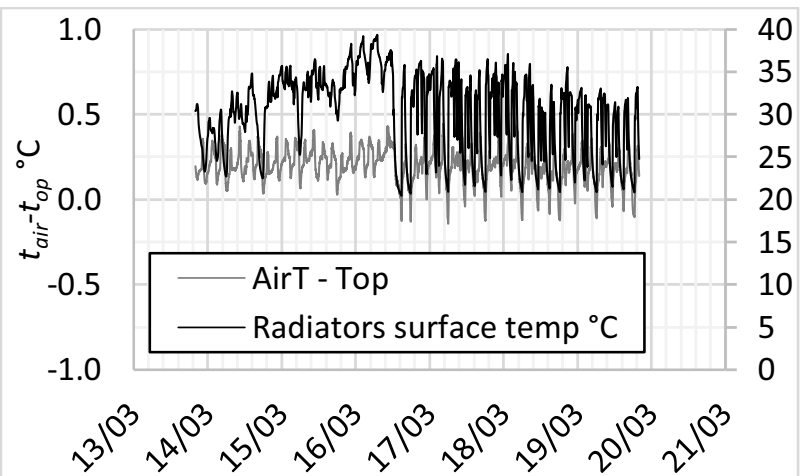

Fig. 15. R9 radiator $t_{\text {air }} \mathrm{t}_{\text {op }}$ difference.

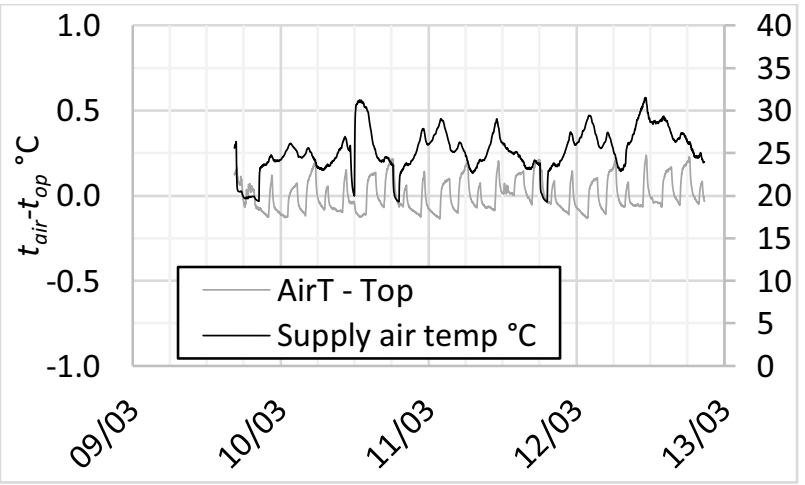

Fig. 16. $R 9$ air heater $t_{a i r}-t_{o p}$ difference.

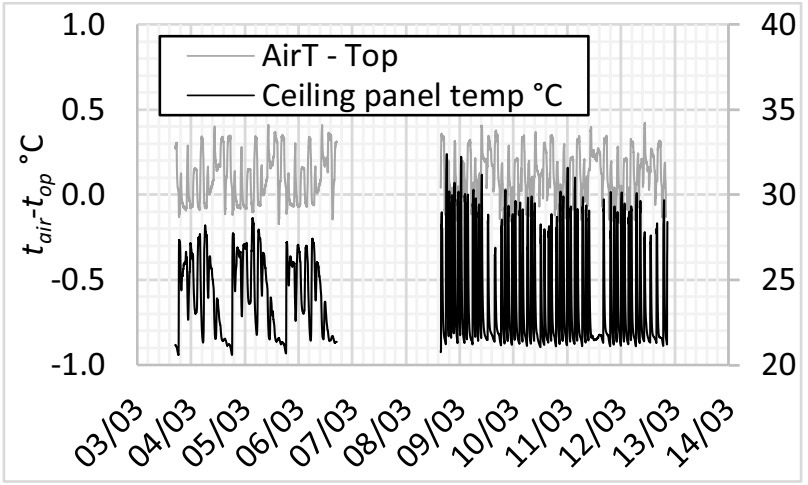

Fig. 17. R5 Ceiling heating $t_{\text {air }}-t_{\text {op }}$ difference.

Table 1. Main measurement and calculation results for different emitter configurations. Lighter cells correspond to lower energy consumption.

\begin{tabular}{|c|c|c|c|}
\hline Type & $\begin{array}{c}\text { Gradient, } \\
{ }^{\circ} \mathbf{C} / \mathbf{m}\end{array}$ & $\begin{array}{c}t_{\text {air }}-t_{\text {op }}, \\
{ }^{\circ} \mathrm{C}\end{array}$ & $\begin{array}{l}\mathrm{CV}, \\
{ }^{\circ} \mathrm{C}\end{array}$ \\
\hline Rad ON/OFF R5 & 0.15 & \multirow{2}{*}{0.26} & 0.45 \\
\hline Rad PI R5 & 0.16 & & 0.36 \\
\hline Rad ON/OFF R9 & 0.08 & \multirow{2}{*}{0.20} & 0.59 \\
\hline Rad PI R9 & 0.10 & & 0.39 \\
\hline UFH ON/OFF R5 & 0.06 & \multirow{2}{*}{0.01} & 0.52 \\
\hline UFH PI R5 & 0.08 & & 0.46 \\
\hline UFH ON/OFF R9 & 0.02 & \multirow{2}{*}{-0.45} & 0.62 \\
\hline UFH PI R9 & 0.04 & & 0.41 \\
\hline Ceiling ON/OFF R5 & 0.52 & \multirow{2}{*}{0.11} & 0.49 \\
\hline Ceiling PI R5 & 0.70 & & 0.44 \\
\hline Air heater ON/OFF R9 & 0.36 & 0.01 & 0.44 \\
\hline
\end{tabular}

\section{Conclusions}

In this study, control variation, vertical temperature stratification and $\left(\mathrm{t}_{\mathrm{air}}-\mathrm{t}_{\mathrm{op}}\right)$ differential were quantified as components of an emitter performance analysis. All three parameters are of interest for both emitter energy consumption and product comparison, as they directly affect the energy usage and thermal comfort within the heated room.

As expected, the PI-type controllers outperformed the ON/OFF-type controllers in regard of control variation.

A notably small vertical temperature gradient and air stratification within the room could be achieved with the UFH $\left(0.04{ }^{\circ} \mathrm{C} / \mathrm{m}\right)$, while configurations where the heat is emitted into the higher part of the room induced a significant temperature gradient, 0.36 and $0.62{ }^{\circ} \mathrm{C} / \mathrm{m}$ for air heater and radiant ceiling panels respectively.

Our results therefore provide a solid basis for further model calibration and set-point variation calculations, in view of annual energy consumption investigations aiming at establishing future international standards.

This research was supported by the Association of the European Heating Industry EHI member companies Irsap Spa, REHAU AG + Co, Stelrad Radiator Group Limited, Uponor Corporation, Vasco Group, Wavin B.V., Rettig Austria, Zehnder Group International AG, and the Estonian Centre of Excellence in Zero Energy and Resource Efficient Smart Buildings and 
Districts, ZEBE, grant 2014-2020.4.01.15-0016 funded by the European Regional Development Fund.

\section{References}

1. B. W. Olesen, E. Mortensen, J. Thorshauge, and B. Berg-Munch, "Thermal comfort in a room heated by different methods," ASHRAE transactions, vol. 86, no. 1, pp. 34-48 (1980).

2. B. W. Olesen and M. de Carli, "Calculation of the yearly energy performance of heating systems based on the European building energy directive and related CEN standards," Energy and Buildings, vol. 43, no. 5, pp. 1040 - 1050 (2011), Tackling building energy consumption challenges - Special Issue of ISHVAC 2009, Nanjing, China.

3. J. Léger, D. R. Rousse, K. L. Borgne, and $\mathrm{S}$. Lassue, "Comparing electric heating systems at equal thermal comfort: An experimental investigation," Building and Environment, vol. 128, pp. 161 - 169 (2018).

4. M. Maivel, A. Ferrantelli, and J. Kurnitski, "Experimental determination of radiator, underfloor and air heating emission losses due to stratification and operative temperature variations," Energy and Buildings, vol. 166, pp. 220 - 228 (2018).

5. EN 15316-2:2017, "Energy performance of buildings. Method for calculation of system energy requirements and system efficiencies. Part 2: Space emission systems (heating and cooling), Module M3-5, M4-5,.” CEN, Standard (2017).

6. K.-V. Võsa, A. Ferrantelli, T. M. Kull, and J. Kurnitski, "Experimental analysis of emission efficiency of parallel and serial connected radiators in en442 test chamber," Applied Thermal Engineering, vol. 132, pp. 531 - 544 (2018).

7. ISO 7726:1998, "Ergonomics of the thermal environment - Instruments for measuring physical quantities," International Organization for Standardization, Standard (1998).

8. EN, "EN 15500-1 Energy Performance of Buildings - Control for heating, ventilating and air conditioning applications," CEN, Standard (2017).

9. A. Mishra, M. Loomans, and J. Hensen, "Thermal comfort of heterogeneous and dynamic indoor conditions - An overview," Building and Environment, vol. 109, pp. 82 - 100 (2016). 